\title{
Laboratory investigation of photochemical oxidation of organic aerosol from wood fires 2: analysis of aerosol mass spectrometer data
}

\author{
A. P. Grieshop ${ }^{1, *}$, N. M. Donahue ${ }^{1}$, and A. L. Robinson ${ }^{1}$ \\ ${ }^{1}$ Center for Atmospheric Particle Studies, Carnegie Mellon University, Pittsburgh, Pennsylvania, USA \\ *now at: Institute for Resources, Environment and Sustainability, University of British Columbia, Vancouver, British \\ Columbia, Canada
}

Received: 11 August 2008 - Published in Atmos. Chem. Phys. Discuss.: 10 September 2008

Revised: 9 March 2009 - Accepted: 11 March 2009 - Published: 27 March 2009

\begin{abstract}
Experiments were conducted to investigate the effects of photo-oxidation on organic aerosol (OA) in dilute wood smoke by exposing emissions from soft- and hardwood fires to UV light in a smog chamber. This paper focuses on changes in OA composition measured using a unit-mass-resolution quadrupole Aerosol Mass Spectrometer (AMS). The results highlight how photochemical processing can lead to considerable evolution of the mass, volatility and level of oxygenation of biomass-burning OA. Photochemical oxidation produced substantial new OA, more than doubling the OA mass after a few hours of aging under typical summertime conditions. Aging also decreased the volatility of the OA and made it progressively more oxygenated. The results also illustrate strengths of, and challenges with, using AMS data for source apportionment analysis. For example, the mass spectra of fresh and aged BBOA are distinct from fresh motor-vehicle emissions. The mass spectra of the secondary OA produced from aging wood smoke are very similar to those of the oxygenated OA (OOA) that dominates ambient AMS datasets, further reinforcing the connection between OOA and OA formed from photo-chemistry. In addition, aged wood smoke spectra are similar to those from OA created by photo-oxidizing dilute diesel exhaust. This demonstrates that the OOA observed in the atmosphere can be produced by photochemical aging of dilute emissions from different types of combustion systems operating on fuels with modern or fossil carbon. Since OOA is frequently the dominant component of ambient OA, the similarity of
\end{abstract}

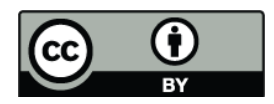

Correspondence to: A. L. Robinson (alr@andrew.cmu.edu) spectra of aged emissions from different sources represents an important challenge for AMS-based source apportionment studies.

\section{Introduction}

Organic aerosols (OA) are a highly-dynamic system dominated by both variable gas-particle partitioning and chemical evolution. The sources of OA are not well understood, especially the relative contributions of primary versus secondary organic aerosol. Primary organic aerosols (POA) are directly emitted by sources; secondary organic aerosols (SOA) are formed in the atmosphere from the oxidation products of gasphase precursors. Recent ambient measurements with the Aerodyne Aerosol Mass Spectrometer (AMS) have shown that oxygenated OA (OOA) is the dominant component of OA in most regions of the atmosphere (Zhang et al., 2007). OOA is strongly correlated with secondary tracers such as inorganic species (Ulbrich et al., 2008; Zhang et al., 2005b) and odd oxygen $\left(\mathrm{O}_{3}+\mathrm{NO}_{2}\right.$; or $\left.\mathrm{O}_{\mathrm{x}}\right)$ (Herndon et al., 2008) in ambient datasets. Therefore, OOA appears related to SOA; however, the AMS mass spectrum of SOA generated in traditional smog chamber experiments is often spectrally distinct from ambient OOA (Bahreini et al., 2005). In addition, field (de Gouw et al., 2008; de Gouw et al., 2005; Volkamer et al., 2006) and laboratory (Grieshop et al., 2009a; Robinson, 2007; Sage et al., 2008; Weitkamp et al., 2007) measurements have shown that gas-phase oxidation can form much more SOA than is predicted by current models.

Published by Copernicus Publications on behalf of the European Geosciences Union. 
Recently, we have shown that photo-oxidation of diluted exhaust from a diesel engine produces substantial amounts of SOA that is spectrally similar to OOA (Robinson, 2007; Sage et al., 2008). Although motor vehicles are an important source of aerosols in urban environments, biomass burning is a much more important source at global scales. For example, biomass-burning is estimated to contribute $90 \%$ of the global emissions of primary particulate organic carbon (OC) from combustion sources (Bond et al., 2004).

Aerosol emissions from biomass burning are often identified using particle constituents such as chloride, potassium and levoglucosan (Simoneit et al., 1999). Recently, the contribution of biomass burning emissions to urban OA concentrations has been estimated by factor analysis of ambient AMS data (DeCarlo et al., 2008; Lanz et al., 2007). However, source apportionment of biomass-burning emissions is complicated by the evolution of these emissions in the atmosphere. For example, dilution measurements show that the gas-particle partitioning of biomass burning emissions depends on atmospheric conditions (Lipsky and Robinson, 2006; Shrivastava et al., 2006). Multiple field studies report substantial in-plume production of OA (Abel et al., 2003; Lee et al., 2008; Nopmongcol et al., 2007; Reid et al., 1998; Reid et al., 2005). Other studies have observed substantial chemical evolution of biomass-burning emissions with atmospheric aging but without additional production of OA (Capes et al., 2008; Hoffer et al., 2006).

This is the second paper in a two-part series that investigates the effects of photo-oxidation on wood smoke. As discussed in the companion paper (Grieshop et al., 2009a), modest amounts of photo-oxidation of diluted wood smoke in a smog chamber produced substantial amounts of SOA. On average, less than $20 \%$ of this new OA could be explained by oxidation of traditional SOA precursors. Results from a volatility basis-set model that explicitly tracks the partitioning and aging of low-volatility organics indicate that the SOA production can be explained by oxidation of low-volatility organic vapors.

In this paper, we focus on the effects of photochemical aging on the composition of OA emitted from biomass burning as measured with an AMS. The specific goals include: 1) quantifying the production of SOA using the spectral decomposition method of Sage et al. (2008); 2) characterizing the evolution of OA composition; and 3) comparing the results from these experiments to AMS data from the literature (laboratory and ambient).

\section{Experimental methods}

Experimental details are discussed in a companion paper (Grieshop et al., 2009a). Briefly, exhaust from wood fires in a small wood stove was injected, via a heated inlet line, into a dark, temperature-controlled $12 \mathrm{~m}^{3}$ Teflon-lined environmental chamber filled with HEPA and activated-carbon filtered air. Upon entering the chamber, the exhaust rapidly mixed and cooled to $22 \pm 2^{\circ} \mathrm{C}$. Initial particle concentrations were tens to hundreds of $\mu \mathrm{g} \mathrm{m}^{-3}$ of predominantly carbonaceous material. The primary emissions were characterized for $\sim 1 \mathrm{~h}$ and then the chamber UV lights were turned on to initiate photo-oxidation reactions. The evolution of the wood smoke was monitored using a suite of gas- and particle-phase instruments.

Separate experiments were conducted with emissions from mixed hardwood, Laurel Oak and Yellow Pine fires burning under a variety of conditions, from smoldering to active flaming combustion. Gas- and particle-phase concentrations inside the chamber were similar to field measurements of fresh biomass plumes (Grieshop et al., 2009a). For example, modified combustion efficiencies (MCE, Koppmann et al., 2005) ranged between 0.58 and 0.93 with a median value of 0.87 . Organic-to-elemental-carbon ratios of the fresh woodsmoke aerosol ranged from 1.1 to 13 . Additional details on the experimental conditions are reported in a companion manuscript (Grieshop et al., 2009a).

This paper focuses on data from a unit-mass-resolution quadrupole Aerodyne Aerosol Mass Spectrometer (AMS) (Canagaratna et al., 2007). The AMS collected data with 5 minute time resolution at a vaporizer temperature of $600^{\circ} \mathrm{C}$, alternating between mass spectrum (MS) scanning, Jump Mass Spectrum (JMS, Crosier et al., 2007) and particle time of flight (PToF, Jimenez et al., 2003) modes. The mass fragments scanned in PToF mode were selected to give information about the size distributions and mixing states of important non-refractory species (organics, nitrate, potassium, etc.). The mass fragments scanned in JMS mode were selected to improve the signal-to-noise ratio for fragments of particular interest in organic mass spectra (e.g. $m / z 44$ and $57)$ and those expected to make significant contributions to wood burning POA $(\mathrm{m} / \mathrm{z} 60,73,137$ and 167, Alfarra et al., 2007; Schneider et al., 2006). Except as noted below, the organic spectra were generated using the default fragmentation table (Allan et al., 2004).

We carefully considered the assignment of the AMS signal at $m / z 28$ and 18. Due to the difficulty of separating the organic particle signal (mostly from $\mathrm{CO}^{+}$) from the large air beam signal (from $\mathrm{N}_{2}^{+}$) at $m / \mathrm{z} 28$, the default fragmentation table in the unit mass resolution AMS data analysis package has traditionally set the organic contribution at $\mathrm{m} / \mathrm{z} 28$ to zero (Allan et al., 2004). However, recent analysis suggests that the OA signal at $m / z 28$ in ambient samples is equivalent to the signal at $m / z 44$ (Aiken et al., 2008, and references therein). In these experiments, we directly estimated the contribution of OA to $m / z 28$ using particle-free samples to establish a baseline signal due to $\mathrm{N}_{2}^{+}$. This estimate is discussed in Sect. 3.2. Another complication is the uncertain contribution from organic dehydration fragments $\left(\mathrm{H}_{2} \mathrm{O}^{+}\right)$at $m / z$ 18. In the original AMS fragmentation table (Allan et al., 2004), OA at $m / z 18$ is set equal to the OA signal at $m / z$ 44; Aiken et al. (2008) recently proposed reducing the OA 
contribution at $m / z 18$ to 0.225 times the $\mathrm{OA}$ signal at $\mathrm{m} / \mathrm{z}$ 44. Here we have chosen to maintain the original fragmentation scheme for $m / z$ 18. Since our wood smoke aerosol was dominated by carbonaceous material there should be minimal particle-bound water under the low relative humidity conditions of these experiments (less than 20\%). In addition, with the default fragmentation table, the AMS particlebound water signal was always positive, which suggests that we have not over-apportioned $\mathrm{m} / \mathrm{z} 18$ to organics. Finally, PToF data generally indicates that the particle signal at $m / z$ 18 is aligned with, and of similar magnitude to, that at $\mathrm{m} / \mathrm{z}$ 44. Updating the fragmentation scheme for $\mathrm{m} / \mathrm{z} 18$ to that proposed by Aiken et al. (2008) only has minor effects on our results; it reduces the signal at $m / z 18$ attributed to OA so the total OA mass decreases by 1 to $7 \%$, which, in turn, slightly increases the fractional contribution of the other peaks to the OA spectrum.

\subsection{Spectral decomposition of the AMS data}

The AMS data were used to estimate the SOA production and mass spectrum using the residual decomposition approach (Sage et al., 2008). This approach uses the AMS signal at a single $m / z$ as a tracer for the POA; we subsequently refer to the chosen $m / z$ as the POA-tracer. The residual spectrum $\left(\mathrm{MS}_{\text {residual }}\right)$ is defined as

$\operatorname{MS}_{\text {residual }}(t)=\operatorname{MS}_{\text {total }}(t)-f_{\text {tracer }}(t) * \mathrm{MS}_{\mathrm{POA}}$

where $\mathrm{MS}_{\text {total }}(t)$ is the measured OA MS at time $t, \mathrm{MS}_{\mathrm{POA}}$ is the POA MS determined by averaging the AMS data for 15 to $25 \mathrm{~min}$ before turning on the chamber lights (i.e. before the initiation of photochemistry). The $\mathrm{MS}_{\mathrm{POA}}$ is scaled based an estimate of the fractional contribution of POA $\left(f_{\text {tracer }}\right)$,

$f_{\text {tracer }}(t)=\frac{m_{\text {tracer }}(t)}{m_{\text {tracer }}\left(t_{0}\right)}$

where $m_{\text {tracer }}(\mathrm{t})$ and $m_{\text {tracer }}\left(\mathrm{t}_{0}\right)$ are the concentrations of a POA-tracer fragment at time $t$ and at "lights-on" $\left(t_{0}\right)$, respectively. $\mathrm{MS}_{\text {residual }}$ provides an estimate of the composition of the SOA.

The results from the residual decomposition method provide an estimate of the SOA production in the chamber. We express this production as an OA enhancement ratio (ER):

$\mathrm{ER}=\frac{m_{\text {total }}}{m_{\mathrm{POA}}}=\frac{1}{f_{\mathrm{POA}}}=\frac{1}{1-f_{\text {residual }}}$

where $m_{\text {total }}$ and $m_{\mathrm{POA}}$ are the organic mass in the entire MS and attributed to the POA MS, and $f_{P O A}$ and $f_{\text {residual }}$ are the fractions of the total organic mass attributed to the POA and residual spectra, respectively.

We decomposed the AMS data using different POA-tracer fragments, including $\mathrm{m} / \mathrm{z} 60,73,137$ and 167; source testing and factor analysis of ambient data indicate that these fragments are strongly associated with POA emissions from biomass combustion (Alfarra et al., 2007; Schneider et al., 2006). We also allowed the POA-tracer to "float" by selecting the fragment which minimizes the value of $f_{\text {tracer }}$ for each individual MS under the constraints that: a) the fragment has a signal-to-noise ratio greater than three and contributes at least $0.5 \%$ of the total mass, and b) the fragment's contribution varies by less than $10 \%$ among the set of AMS scans averaged to define $\mathrm{MS}_{\mathrm{POA}}$.

Key assumptions of the residual decomposition approach are that the POA spectrum is constant in time and that the POA-tracer fragment is a conserved tracer for the POA (Sage et al., 2008). This means that POA composition can not evolve due to heterogeneous processing or changes in gasparticle partitioning. For example, if a compound associated with the POA-tracer fragment is heterogeneously oxidized or evaporates during an experiment then the spectral decomposition method will underestimate the contribution of POA. Alternatively, if a compound that contributes to the POAtracer fragment is produced by secondary chemistry then the spectral decomposition method will overestimate the contribution of POA. Uncertainties associated with these assumptions are discussed below.

Although the residual method uses an individual AMS mass fragment as a tracer for the POA, this fragment likely does not correspond to a specific compound given the extensive and complex fragmentation that occurs inside the AMS. Therefore, our approach is distinct from studies that use individual organic compounds or "molecular markers" as markers or tracers for specific source classes (e.g. Robinson et al., 2006; Schauer et al., 1996). Molecular markers are more source-specific than the AMS fragments considered here.

\subsection{OA Volatility}

Particle volatility was measured with a thermodenuder (TD) system that first heated the aerosol and then stripped the evaporated gas-phase components using an activated-carbon denuder (An et al., 2007). Gas temperatures in the heated zone ranged between 50 and $85^{\circ} \mathrm{C}$; the ambient temperature centerline residence time in the heated section was approximately $16 \mathrm{~s}$. Measurements were made with the AMS downstream from the TD system and a bypass line maintained at $25^{\circ} \mathrm{C}$. The AMS was switched between these two lines every 15 to $30 \mathrm{~min}$.

$\mathrm{OA}$ evaporation in the TD is quantified using the mass fraction remaining (MFR):

$\mathrm{MFR}=\frac{C_{\mathrm{TD}}}{C_{\text {bypass }}}$

where $C_{\mathrm{TD}}$ and $C_{\text {bypass }}$ are the AMS concentrations measured downstream of the TD and bypass lines, respectively. MFRs were calculated for the bulk OA and individual AMS mass fragments. Total number loss in the TD system was found to be less than 2\% (An et al., 2007) and loss of nonrefractory mass measured by the AMS was less than 5\% at 


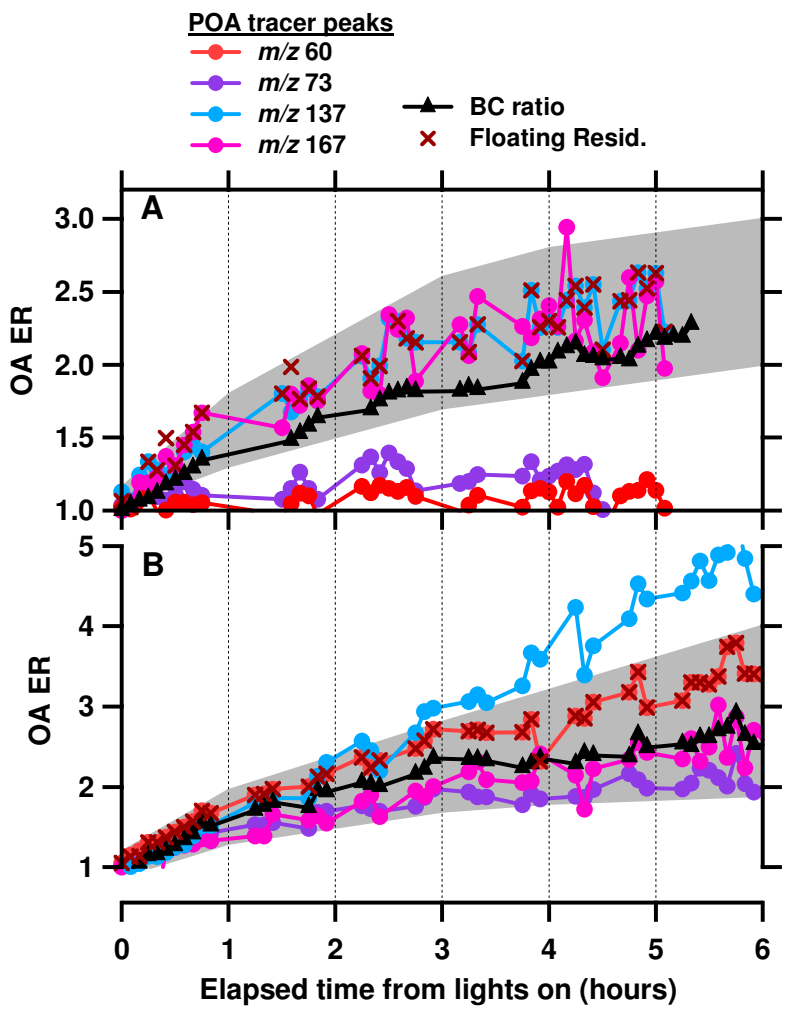

Fig. 1. OA enhancement ratios (ER) calculated using different POA tracers $(m / z 60,73,137$ and 167 and black carbon - BC). The data in Panel (A) are from an experiment with smoldering oak emissions (experiment \#3); the data in Panel (B) are from a smoldering yellow pine emissions (experiment \#5). Additional experimental details can be found in Tables 1 and 2 of the companion manuscript (Grieshop et al., 2009a) Gray areas indicate the range of OA ER estimates.

ambient temperatures. TD loss corrections are addressed in detail in other analyses (Grieshop, 2009b) but had relatively little effect on our results. No corrections were made for these losses.

\section{Results}

\subsection{SOA production estimates via spectral decomposi- tion}

Photo-oxidation of the diluted wood smoke inside the chamber created substantial new SOA mass (Grieshop et al., 2009a). Figure 1 compares estimates of SOA production derived using the residual decomposition method to results based on using black carbon (BC) as the tracer for POA. The BC-based approach is discussed in the companion manuscript (Grieshop et al., 2009a). The results are presented in terms of an OA enhancement ratio (ER), which quantifies SOA production relative to the initial POA concentration. For example, an OA ER of two indicates that photo-oxidation has doubled the wall-loss corrected OA concentration in the chamber. Figure 1 plots OA ERs calculated using different mass fragments associated with wood smoke POA ( $m / z$ 60, 73, 137 and 167) (Alfarra et al., 2007; Schneider et al., 2006) and the floating-tracer residual method described in Sect. 2.1. The grey areas shown in Fig. 1 indicate the range of OA ER estimates based on different techniques.

The floating-tracer method predicts that photo-oxidation doubles or triples the wall-loss-corrected OA mass after about five hours under typical summertime conditions. This level of SOA production is comparable to estimates that use $\mathrm{BC}$ as the tracer for POA (Grieshop et al., 2009a). However, the POA-tracer fragment identified by the floatingtracer method varied from experiment to experiment. In the two experiments shown in Figure 1, the floating-tracer method identified $m / z 137$ and 167 as the tracer fragment for primary emissions in one experiment (Fig. 1a) and $\mathrm{m} / \mathrm{z}$ 60 in a second (Fig. 1b). In other experiments (not shown) the floating tracer method identified $\mathrm{m} / \mathrm{z} 113,165$ and 152 as POA-tracers. In contrast, application of the floating tracer method to diesel exhaust experiments always identifies $\mathrm{m} / \mathrm{z}$ 57 as the POA-tracer fragment (Sage et al., 2008). This highlights the inherent variability in wood-smoke POA and the challenges associated with using a single AMS fragment as a tracer for biomass-burning POA.

The results shown in Fig. 1 underscore some of the challenges and uncertainties associated with the residual decomposition method. For example, different POA-tracers can provide very different estimates of the OA ER or SOA production. Some of this variability is caused by problems with the assumptions underlying the residual decomposition method. For example, in every experiment at least one of the AMS mass fragments commonly associated with wood smoke POA yielded an outlier estimate for the SOA production. For example, using either $m / z 60$ or 73 as the POAtracer greatly underestimated the SOA production in the experiment shown in Fig. 1a. In this experiment (and two others, see Fig. $5 \mathrm{~b}$ for $m / z 60$ data) the relative contributions of $m / z 60$ and 73 were very low and did not change with aging. The likely explanation is secondary production of compounds that contribute to the AMS signal at these mass fragments. Secondary production contributing to the signal at the POA-tracer fragment violates one of the assumptions underlying the residual decomposition technique. This hypothesis is supported by smog-chamber experiments with traditional SOA precursors that produce modest amounts of organic mass at $m / z 60$ (between 0.3 and $0.6 \%$ of the total signal) (Bahreini et al., 2005; Ulbrich and Jimenez, 2008). In addition, ambient OOA spectra in the absence of strong biomass-burning influence have $\sim 0.2-0.3 \%$ of the signal at $\mathrm{m} / \mathrm{z} 60$ (Ulbrich et al., 2008; Zhang et al., 2005a). This highlights the challenge of associating individual AMS mass fragments with emissions from a particular source.

Another challenge was defining the $\mathrm{MS}_{\mathrm{POA}}$ because, in some experiments, the AMS OA MS evolved before the UV 

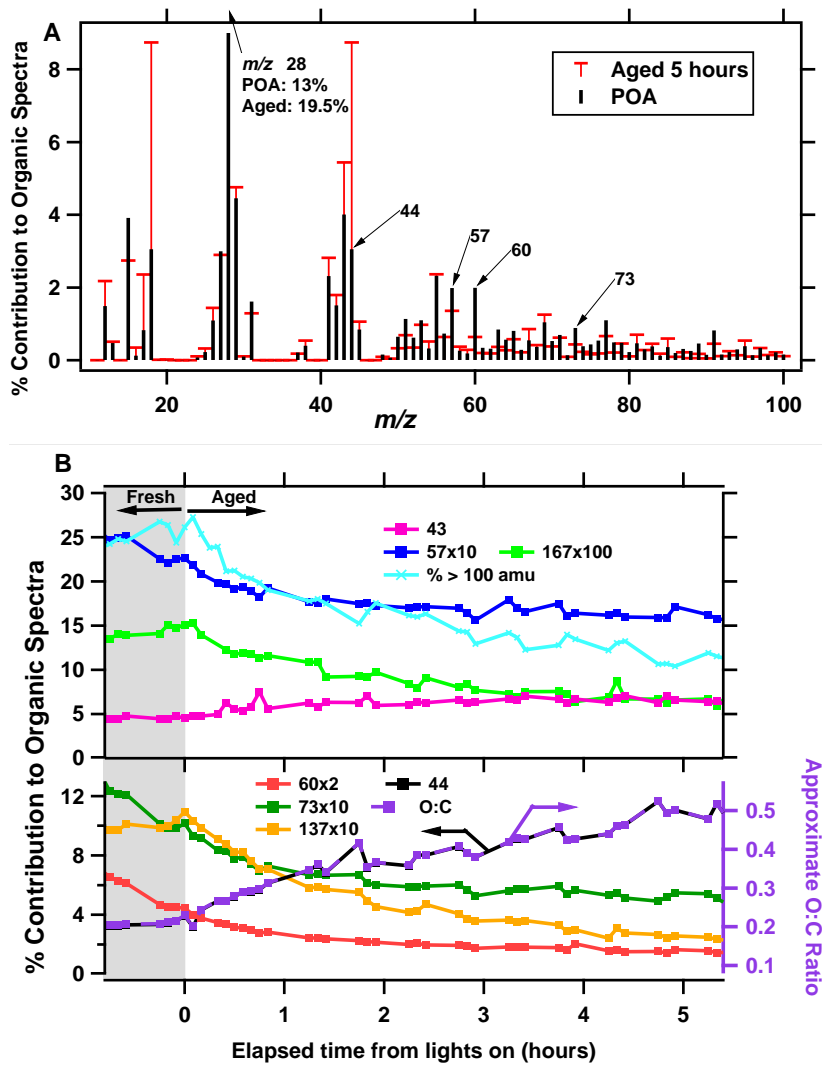

Fig. 2. (A) Mass spectra of fresh and aged wood smoke OA. (B) Time series of key AMS mass fragments: $m / z$ 60, 73, 137 and 167 are indicators of primary or fresh wood smoke emissions; and $m / z 44$ and 43 are indicators of oxidation and aging. Fractional contributions are shown relative to the OA mass neglecting the contribution from $m / z 28$ to facilitate comparison with published AMS data. Including the additional mass at $m / z 28$ would decrease these values by $15-25 \%$. The signals for $m / z 57,60,73,137$ and 167 have been scaled by the factors listed in the legend of panel B. Data are from Experiment 5 (smoldering experiment with Yellow Pine) listed in Table 1 and 2 of the companion manuscript (Grieshop et al., 2009a).

lights were turned on. For example, Fig. $2 b$ shows the fractional contribution of $\mathrm{m} / \mathrm{z} 60$ and $\mathrm{m} / \mathrm{z} 73$ decreased over the approximately hour-long period before the lights were turned on. We attribute this decrease to evaporation or decomposition of the compound(s) that contribute to these fragments before (and potentially while) the lights were turned on (see discussion in Sect. 3.2). This would violate the assumption of a constant POA spectrum. However, the ER estimates were not highly sensitive to which POA spectra from different "pre-lights" periods was used in the MS decomposition method. For example, in Experiment 5 (Fig. 1b) ER values calculated using different $\mathrm{MS}_{\mathrm{POA}}$ range from 2.8 to 3.2 after $6 \mathrm{~h}$ of aging, which is within the shaded bands demarcating the range of ER estimates from different techniques.
Finally, in the experiment shown in Fig. 1b, the OA ER estimated using $\mathrm{m} / \mathrm{z} 137$ as the POA-tracer is substantially higher than the other estimates. This means that the relative contribution at $m / z 137$ decreased more quickly than the other peaks, potentially due to heterogeneous oxidation and/or preferential evaporation. Note that the floating-tracer method did not select $m / z 137$ in this experiment because of the signal-to-noise ratio cut-off. The TD data discussed below support the aging hypothesis because $m / z 137$ was found to be a fragment associated with the least-volatile material in these experiments.

The results in Fig. 1 and the preceding discussion indicate that the assumptions behind the residual decomposition technique are not strictly valid. This is not surprising given the extensive fragmentation that occurs inside of the AMS. While multiple POA-tracer fragments do provide estimates of SOA production that are consistent with estimates based on independent techniques (such using BC as a tracer for POA) in each experiment, the same POA-tracers did not work for every experiment. Therefore, the residual technique can provide reasonable estimate of SOA formation, but one must consider multiple POA-tracer peaks and compare SOA estimates based on different analysis techniques. Finally, heterogeneous oxidation and evolving source profiles not only present challenges to the residual decomposition approach, but also to molecular marker based source apportionment methods (Subramanian et al., 2006; Weitkamp et al., 2008b).

The particle size distributions measured by the AMS provide another indication of the substantial production of SOA during photo-oxidation. Figure 3 shows size distributions for selected AMS fragments associated with primary $(\mathrm{m} / \mathrm{z}$ 60 and $m / z$ 39) and secondary material $(\mathrm{m} / z 44$ and $m / z$ 46). The fragment at $m / z 44\left(\mathrm{CO}_{2}^{+}\right)$is associated with oxygenated organics (Zhang et al., 2005a; Zhang et al., 2005b), while $\mathrm{m} / \mathrm{z} 60$ is a marker for wood-smoke POA (Alfarra et al., 2007; Schneider et al., 2006). Both potassium and organics contribute to the AMS signal at $m / z$ 39. Nitrate and organics contribute to the AMS signal at $m / z$ 46. Figure 3a shows that in our fresh wood-smoke all of these fragments have a modal vacuum aerodynamic diameter $\left(d_{v a}\right)$ of about $180 \mathrm{~nm}$. Figure $3 \mathrm{~b}$ indicates that aging increased the mode of the particle size distribution to about $250 \mathrm{~nm}$ and increased the relative contribution of secondary fragments $(\mathrm{m} / \mathrm{z} 44$ and 46); clear evidence of particle growth driven by condensation of secondary species. All of the mass fragments have essentially the same size distribution in both the fresh and aged aerosol, which suggests that the particles are internally mixed. The lone exception to this is the PToF data at $\mathrm{m} / \mathrm{z} 44$ which shows a slight bias towards larger sizes (longer times) in both the fresh and aged size distributions. This is likely due to the longer vaporization time of more oxidized material on the AMS heater and not difference in mixing state. 


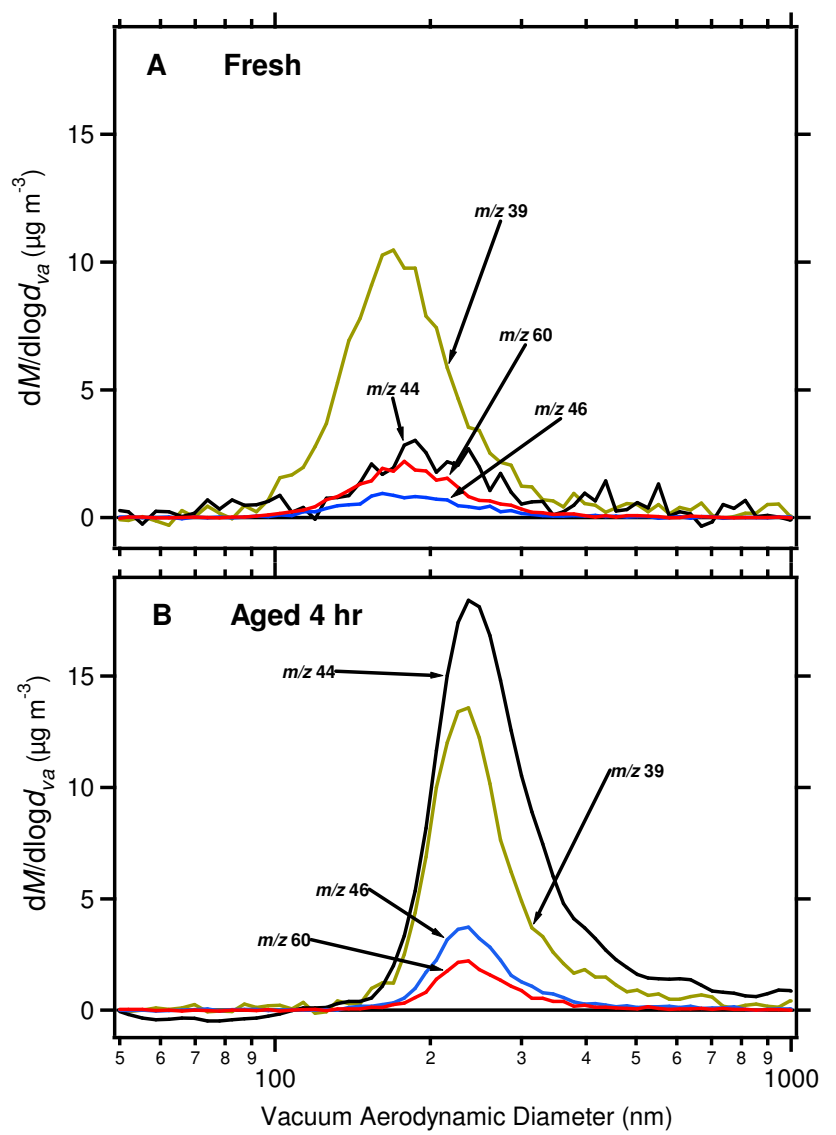

Fig. 3. Size distribution of select AMS fragments of (A) fresh and (B) aged Yellow Pine wood emissions (Experiment 4). Additional experimental details are listed in Tables 1 and 2 of the companion manuscript (Grieshop et al., 2009a).

\subsection{Evolution of OA chemical composition}

The AMS data provide insight into the evolution of the chemical nature of the OA. The AMS does not provide molecular-level information, but characterizes the evolution of the chemical functionality of the OA. Figure 2a compares OA MS from a smoldering Yellow Pine fire measured before and after aging. The spectrum of the fresh POA is qualitatively similar to published wood-burning spectra (Alfarra et al., 2007; Schneider et al., 2006) with dominant peaks at $\mathrm{m} / \mathrm{z}$ $15,18,27,29,41$ and 43 . After $5 \mathrm{~h}$ of aging, the relative contributions from peaks associated with oxygenated $\mathrm{OA}$, such as $m / z 29\left(\mathrm{CHO}^{+}\right), 43\left(\mathrm{C}_{2} \mathrm{H}_{3} \mathrm{O}^{+}\right.$, also $\left.\mathrm{C}_{3} \mathrm{H}_{7}^{+}\right)$and $44\left(\mathrm{CO}_{2}^{+}\right)$ have grown significantly. There is also substantial particle signal at $m / z 46$ in the aged spectra, evidence of the production of nitrate (presumably organic nitrate due to the lack of ammonium in the chamber) during the photo-oxidation.

A noteworthy difference between the spectra shown in Fig. 2a and previously published AMS results is that $\mathrm{m} / \mathrm{z}$ 28 is the largest contributor to the OA mass spectrum. This was observed in every experiment. Evidence for the sub-
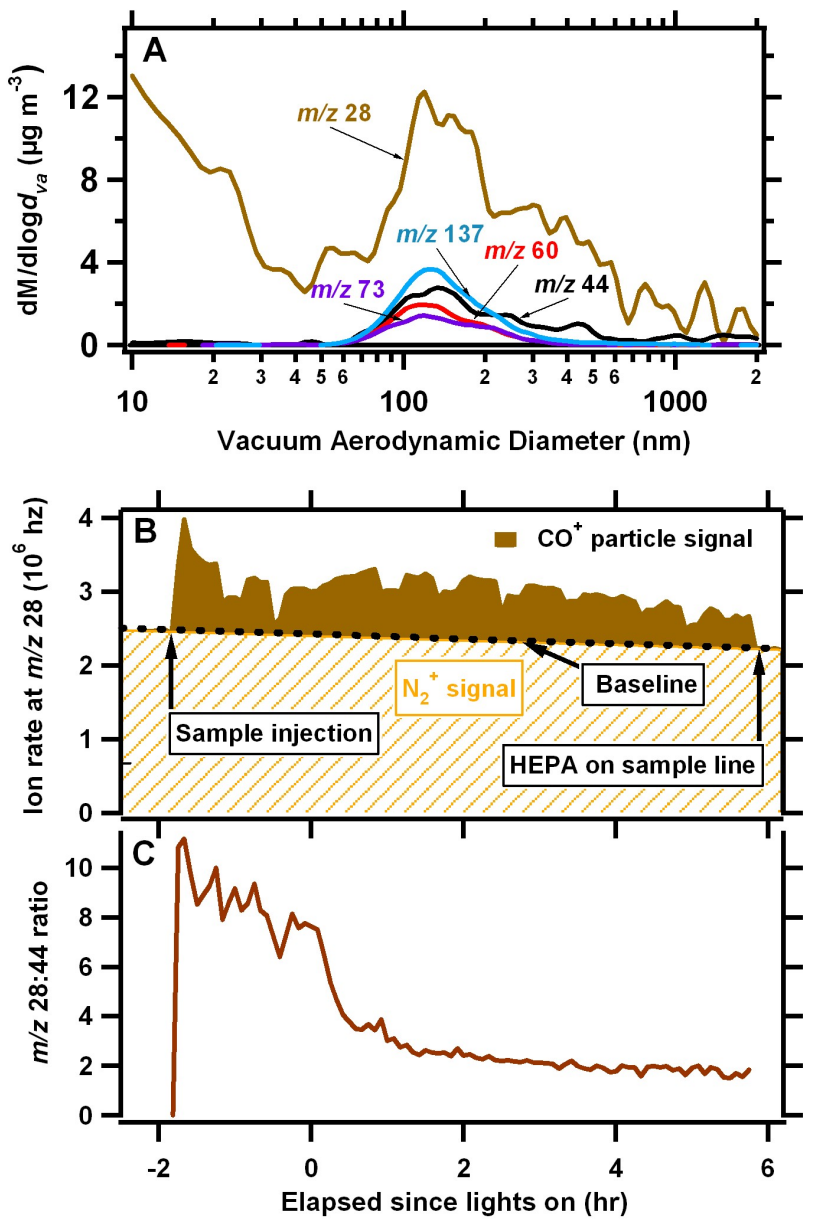

Fig. 4. Evidence for the substantial contribution of OA to the AMS signal at $m / z$ 28. (A) Size distributions of key mass fragments. Time series of (B) $m / z 28$ ion rate and (C) ratio of estimated particle contribution at $m / z 28$ to that at $m / z 44$. The hatched area in (B) indicates the AMS signal apportioned to gas-phase $\mathrm{N}_{2}^{+}$; the filled area indicates the signal apportioned to particle-phase $\mathrm{OA}\left(\mathrm{CO}^{+}\right)$. Data are from a high-mass concentration flaming Yellow Pine experiment (Experiment 4) (Grieshop et al., 2009a).

stantial OA signal at $m / z 28$ is shown in Fig. 4. Figure 4a shows size distributions of selected $m / z$ measured in PToF mode. The signal at $m / z 28$ is large at small diameters due to gas-phase $\mathrm{N}_{2}^{+}$but there is also a clear particle-phase signal peaking at approximately $150 \mathrm{~nm}$ that is aligned with the other $\mathrm{m} / \mathrm{z}$ from wood-smoke POA, including 44, 60, 73 and 137. Additional evidence of the contribution of particle mass to the AMS signal at $m / z 28$ in these experiments is shown in Fig. 4 b, which plots a time series of the raw ion signal at $m / z$ 28. The dashed line and lower hatched area indicate the baseline signal from gas-phase $\mathrm{N}_{2}^{+}$derived from measurements made on HEPA-filtered chamber air at the beginning and end of the experiment. The dashed line is a linear interpolation between these measurements. The baseline $\mathrm{m} / \mathrm{z}$ 28 signal shows the expected decay due to degradation of the 


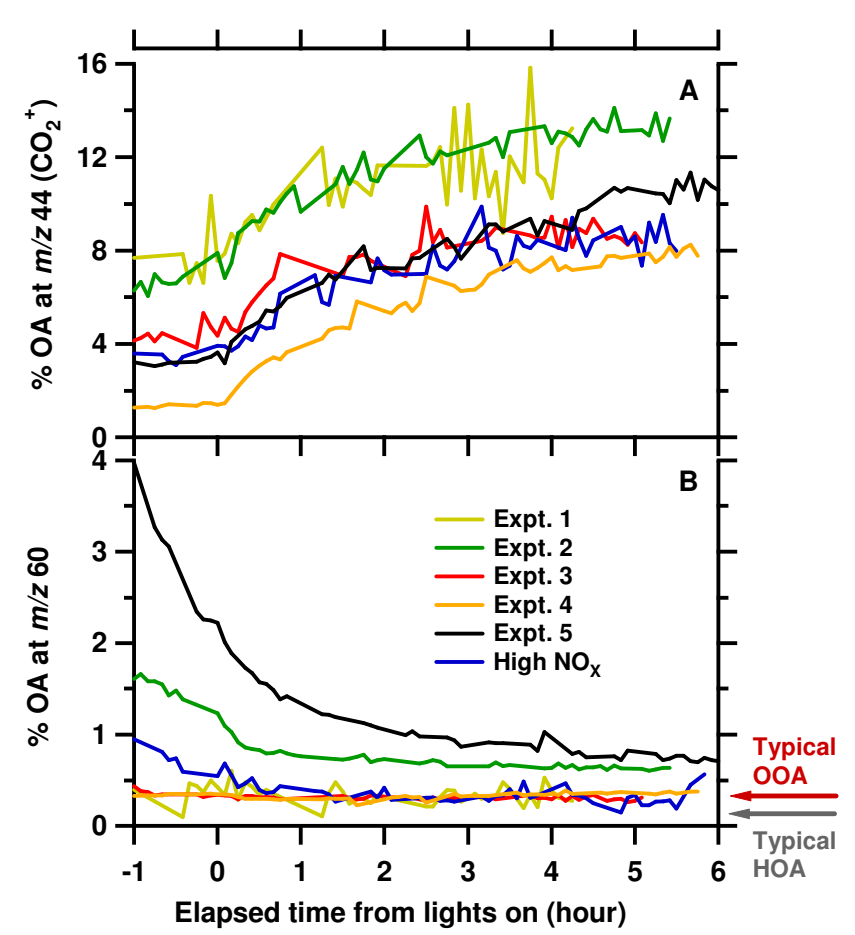

Fig. 5. Time series of fractional contributions from $m / z 44$ and 60 to total OA mass measured in each experiment. Fractional contributions are shown relative to the OA mass neglecting the contribution from $m / z, 28$ to facilitate comparison with published AMS data. Arrows in (B) show contribution at $m / z 60$ in typical OOA and HOA spectra (see e.g. Zhang et al., 2005b). See the companion manuscript (Grieshop et al., 2009a) for experimental details.

AMS electron multiplier during the experiment (Allan et al., 2003). Figure $4 \mathrm{~b}$ shows that there was a substantial increase in the $m / z 28$ signal above this baseline when wood smoke was injected into the chamber.

We estimated the particle-phase contribution at $m / z 28$ as the signal above the baseline air-beam signal shown in Fig. $4 \mathrm{~b}$ and using the PToF gas- and particle-phase data (see Zhang et al., 2005a for description of method). These two estimates were generally within $\pm 25 \%$ of each other. Figure $4 \mathrm{c}$ plots the time series of the ratio of the organic mass at $m / z 28$ to that at $m / z 44$. In this experiment, $m / z 28$ initially contributes 8 times more OA than $m / z 44$. Across the entire set of experiments, $\mathrm{m} / z 28$ contributed 10 to $25 \%$ of the fresh wood-smoke POA, a factor of 4 to 10 higher than the organic contribution at $m / z 44$. Figure $4 \mathrm{c}$ indicates that this ratio decreased rapidly to around two after about half an hour of photochemical aging.

Previous studies have shown that the organic signal at $\mathrm{m} / \mathrm{z}$ 28 can be comparable or larger than that at $m / z 44$ for ambient organics (Aiken et al., 2008; Takegawa et al., 2007; Zhang et al., 2005a). Aiken et al. (2008) have proposed that the organic fragmentation table used in the AMS software for ambient studies be updated to set the organic contribution at $m / z 28$ (mostly $\mathrm{CO}^{+}$) equal to that at $m / z$ 44. Our results suggest that this may be too small for fresh wood smoke samples. Although $m / z 28$ appears to be an important contributor to the OA MS in these experiments, we neglect its contribution in plots of fragment contributions (Figs. 2b, 5 and 7) in order to facilitate direct comparisons of our data with published AMS data that are based on the Allan et al. (2004) fragmentation table.

Figure $2 \mathrm{~b}$ shows a time series of the fractional contribution of select AMS mass fragments to the total OA MS from a typical experiment. First we discuss fragments associated with wood smoke POA, $m / z$ 60, 73, 137 and 167 (Alfarra et al., 2007; Schneider et al., 2006), and $m / z 57\left(\mathrm{C}_{4} \mathrm{H}_{9}^{+}\right.$, but also $\mathrm{C}_{3} \mathrm{H}_{5} \mathrm{O}^{+}$) which is commonly associated with reduced organics emitted from fossil-fuel combustion sources (Zhang et al., 2007). After the lights were turned on, the relative contribution of all of these POA-associated peaks decreased, especially during the first $2 \mathrm{~h}$ of aging. This decrease is due to the production of substantial amounts of SOA.

As discussed above, Fig. $2 b$ also indicates that the fractional contribution of some of the primary fragments $(\mathrm{m} / \mathrm{z}$ 57, 60 and 73) also decreased before the UV lights were turned on. We attribute this decrease to evolving gas-particle partitioning associated with the initial dilution that occurred when the exhaust was injected into the chamber. In-chamber dilution experiments have shown that equilibration after dilution can occur on time scales on the order of hours. (Grieshop et al., 2007, 2009b). There was also a slight decrease (approximately $15 \%$ ) in the OA-to-BC ratio during this initial (pre-lights) mixing period, supporting the hypothesis of slow evaporation of POA. Finally, as discussed below, the TD measurements indicate that $m / z 57,60$ and 73 are some of the most volatile fragments in the AMS spectra. Alternatively, condensed-phase chemistry could also have caused the concentrations of species that contribute to the AMS signal at $m / z 57,60$ and 73 to decrease before the UV lights were turned on.

Figure $2 b$ also plots time series of AMS mass fragments associated with OOA components, such as $m / z 44$ and 43 . The fractional contributions at $m / z 44$ and 43 to total OA mass have been used as an indicator of OOA and OOA-II, respectively, in ambient data sets (Ulbrich et al., 2008; Zhang et al., 2005a; Zhang et al., 2007). The relative contribution of $\mathrm{m} / z, 44\left(\mathrm{CO}_{2}^{+}\right)$increased throughout the aging phase of every experiment, mirroring the production of SOA. This means that SOA formed during photo-oxidation was more oxygenated than the fresh POA. In this experiment, the fractional contribution at $\mathrm{m} / \mathrm{z} 43$ increased from 4 to $6 \%$ of the OA mass within the first $2 \mathrm{~h}$ of aging, after which it remained constant. $m / z 43$ is associated with both hydrocarbon/primary $\left(\mathrm{C}_{3} \mathrm{H}_{7}^{+}\right)$and oxygenated/secondary $\left(\mathrm{C}_{2} \mathrm{H}_{3} \mathrm{O}^{+}\right)$ components of the aerosol. The relative contribution at $\mathrm{m} / \mathrm{z}$ 28 also increased with aging, but less than that at $m / z$ 44. As a result, the approximate ratio of $m / z 28$ and 44 was reduced from 4 to 2 during aging. 


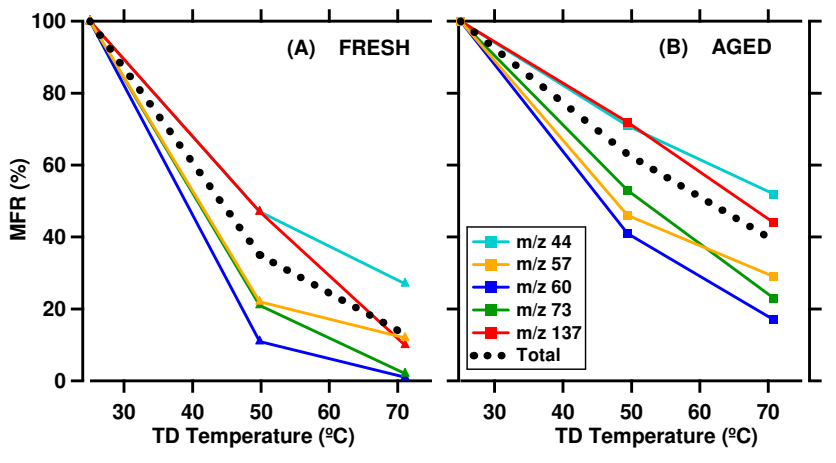

Fig. 6. Average thermograms of thermodenuder MFR data for (A) fresh and (B) aged wood smoke OA. The dash lines indicate average of MFR of the entire OA. The colored symbols indicate data for selected AMS mass fragments. The lines are intended to guide the eye.

High molecular weight mass fragments contribute a substantial fraction of the wood smoke POA. Figure $2 \mathrm{~b}$ shows that approximately $25 \%$ of the initial OA mass is found at mass fragments with $m / z$ larger than 100 ; after $5.5 \mathrm{~h}$ of aging the contribution of these fragments drops to $11 \%$. Therefore, the SOA is composed of smaller molecules and/or species less resistant to fragmentation in the AMS. High molecular weight fragments contribute an even smaller fraction $(\sim 3 \%)$ of ambient OOA spectra (Zhang et al., 2005a).

To illustrate the experiment-to-experiment variability in the AMS data, Fig. 5 plots the time series for the fractional contribution for two important mass fragments, $m / z 44$ and 60 , measured in all of the experiments, which spanned a range of burning conditions and fuel types (Grieshop et al., 2009a). Figure 5a shows that the contribution from $\mathrm{m} / \mathrm{z} 44$ increased during photo-oxidation in every experiment. For the oak experiments, the initial contribution at $m / z 44$ ranged from 4 to $8 \%$ (3.5 to $5.5 \%$ if the contribution $m / z 28$ is included in the OA mass) and was enhanced by a factor of 1.6 to 2 with aging. Pine experiments had initial $\mathrm{m} / \mathrm{z} 44$ contributions of 1.5 to $3.9 \%$ (1.2 to $3 \%$ if the particle contribution at $m / z 28$ is accounted for) which were enhanced by a factor of 2.2 to 5.6 with aging. Therefore, in every experiment, photo-oxidation created more oxygenated OA.

Figure $5 \mathrm{~b}$ indicates that the fractional contribution at $\mathrm{m} / \mathrm{z}$ 60 varied widely from experiment to experiment. In some experiments $\mathrm{m} / \mathrm{z} 60$ contributed 1 to $4 \%$ of the POA mass, comparable to the 0.5 to $4 \%$ range reported for fresh biomass burning emissions (Schneider et al., 2006). However, in other experiments, $m / z 60$ contributed minimally to the POA (less than $0.5 \%$ ), and the fractional contribution at this fragment did not change with aging, consistent with some secondary production. If $m / z 60$ is used as the POA-tracer in these experiments the residual decomposition method predicts very little SOA production (e.g. Fig. 1a). The contributions of $\mathrm{m} / z$ 44 and 60 to our POA spectra are more consistent with previously published spectra for emissions from flaming combus- tion than those from smoldering combustion (Weimer et al., 2008).

Figure 6 plots TD measurements of fresh and aged OA MFR as a function of thermodenuder temperature. The results are averages across all of the experiments. Although Fig. 6 is based on average data, the trends discussed were observed in every experiment. The volatility of the bulk OA is discussed in detail in the companion paper (Grieshop et al., 2009a). Figure 6 indicates that, on average, about $60 \%$ of the fresh POA evaporated at $50^{\circ} \mathrm{C}$ and that aging decreased the volatility of the OA.

The MFR data for individual mass fragments plotted in Fig. 6 indicate that POA is comprised of material with a wide range of volatility. Compounds that contribute to the AMS signal at $m / z 60,73$ and 57 were among the mostvolatile components of POA, while species contributing to $m / z 137$ were among the least-volatile. The AMS signal at $m / z 60$ and 73 has been associated with levoglucosan (Alfarra et al., 2007; Schneider et al., 2006), which can be a major component of biomass burning POA (Reid et al., 2005). However, levoglucosan has an effective equilibrium saturation concentration $\left(\mathrm{C}^{*}\right)$ of order $0.1 \mu \mathrm{g} \mathrm{m}^{-3}$ at ambient temperatures (Milosavljevic et al., 1996), which means that it should start to evaporate at temperatures around $60^{\circ} \mathrm{C}$ - significantly higher than the observed evaporation temperature of species contributing ions at $m / z 60$ and 73. Therefore, levoglucosan may not be the dominant contributor to the AMS signal at $m / z 60$ and 73 in these experiments. Interestingly, aging increased the temperature required to evaporate the same amount of the material commonly associated with POA. However, the relative volatility of the different fragments in the aged aerosol (Fig. 6b) is similar to that in fresh OA (Fig. 6a), but shifted to roughly align with the behavior of the bulk OA. Therefore, even after aging, material associated with $m / z 60,73$ and 57 was substantially more volatile than the bulk OA. The cause for this apparent shift in volatility is not known. This shift could indicate an actual change in volatility due to secondary production of less volatile compounds that contribute to the AMS signal at $m / z 60,73$ and 57 or the shift may due to differences in the evaporation rates of fresh and aged aerosol inside the thermodenuder. For example, larger particles evaporate more slowly than smaller particles and SOA production significantly increases the particle size.

Figure 6 shows that material contributing to the AMS signal at $m / z$ 44 is always less volatile than the bulk OA, indicating that the more oxidized components of OA have lower volatilities. For example, partial evaporation in the TD increases the fractional contribution of $m / z$ 44. This is illustrated in Fig. 7, which presents time series of the fractional contribution at $m / z \quad 44$ and thermodenuder data measured during an experiment conducted with emissions from smoldering Yellow Pine. This has been previously shown in both laboratory and field studies (Grieshop et al., 2007; Huffman et al., 2009). 


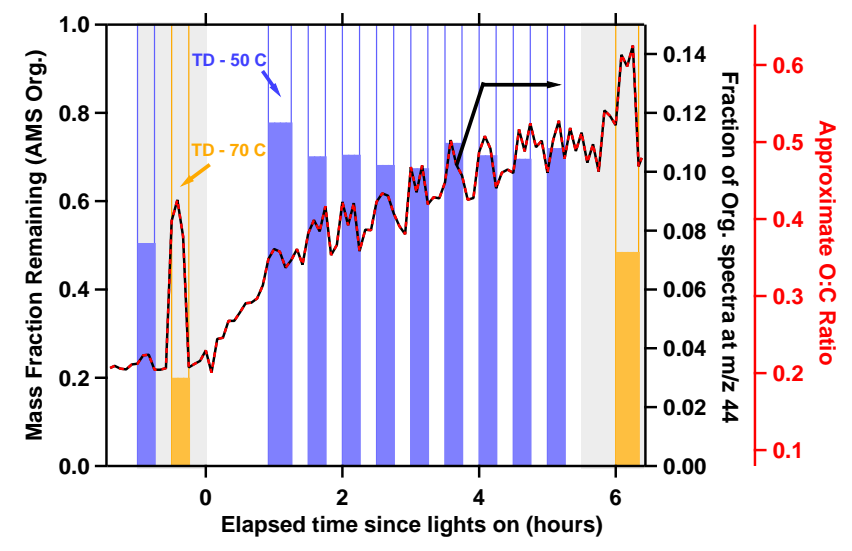

Fig. 7. Time series of measured $\mathrm{OA} \mathrm{MFR}$ at 50 and $70^{\circ} \mathrm{C}$ (left axis) and fractional contribution at $m / z, 44$ (right axis). Bars show periods when sample was drawn through the thermodenuder and the filled portion of the bar indicates the OA MFR. Also shown is an estimate of $\mathrm{OA}$ atomic $\mathrm{O}: \mathrm{C}$ ratio based on the relation from Aiken et al. (2008). Fractional contribution at $m / z 44$ shown relative to the OA mass neglecting the contribution from $\mathrm{m} / \mathrm{z} 28$ to facilitate comparison with other AMS data.

Figure 7 indicates that the fractional contribution of $\mathrm{m} / \mathrm{z}$ 44 is not a perfect indicator of the overall OA volatility in these experiments. For example, aging caused the fractional contribution of $\mathrm{m} / \mathrm{z} 44$ to monotonically increase throughout every experiment, but the OA MFR measured at $50^{\circ} \mathrm{C}$ shows a step change in volatility (see also Fig. 5 in the companion manuscript, Grieshop et al., 2009a). This requires that the volatility of the SOA evolved over the course of the experiment. Specifically it implies that the SOA that was created during the first hour of the experiment was somewhat less volatile and less oxygenated than that formed later in the experiment. This can occur because volatility depends on molecular weight, functionality, and extent of oxygenation. For example, the initial burst of SOA formation could be associated with oxidation of relatively non-polar semivolatile vapors that create very low-volatility but not very oxygenated products. Later in the experiment secondand third-generation precursors may become more important. These later-generation precursors may have lower molecular weights than the first-generation precursors due either to fragmentation or multigenerational processing of initially more volatile precursors. In this situation, the SOA formed from later-generation precursors could be highlyoxygenated, but not necessarily less volatile than the first generation SOA.

\subsection{Intercomparison of AMS spectra}

Figure 8 compares AMS organic spectra from a pine-fire aging experiment to an OOA spectrum derived from the ambient data. Fig. 8a is an average of the fresh (un-aged) woodsmoke POA measured before the chamber lights were turned

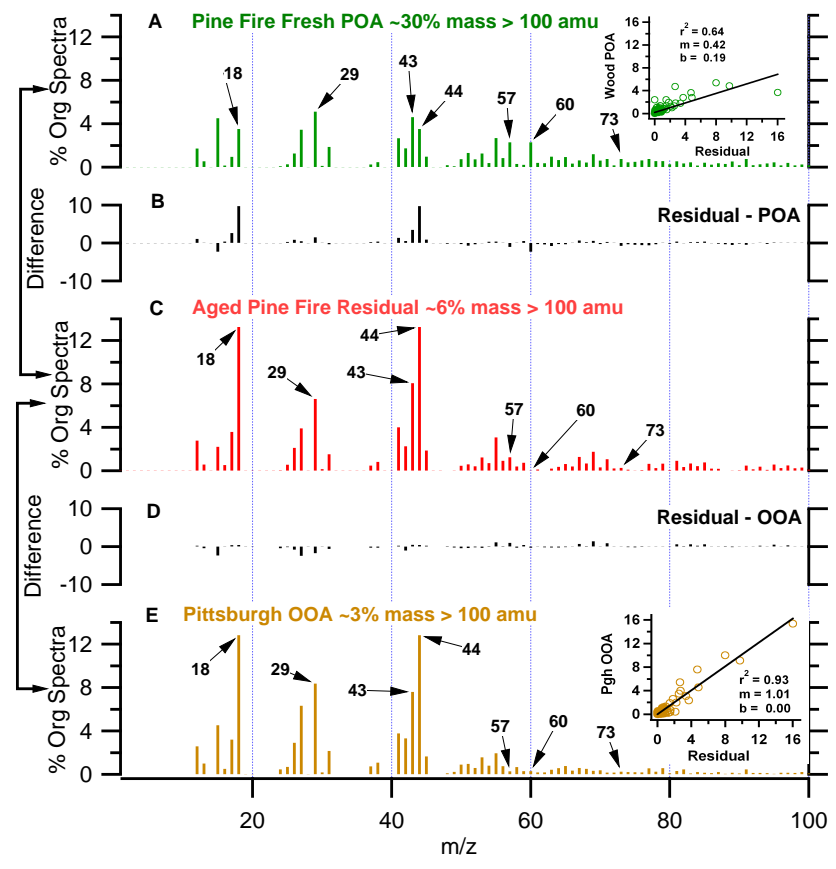

Fig. 8. Comparison of AMS spectra of: (A) fresh wood smoke OA, (C) residual of aged wood smoke OA; and (E) the OOA factor extracted from Pittsburgh ambient measurements (Zhang et al., 2005a). Panel (B) shows the difference spectrum between fresh wood smoke (panel A) and residual of wood smoke (panel C). Panel (D) shows the difference spectrum between the residual spectrum (panel C) and Pittsburgh OOA (panel E). Contributions at $m / z 28$ in the laboratory spectra have been zeroed and the spectra renormalized to allow direct comparison with Pittsburgh OOA. The inset scatter plots show linear regressions of the wood-smoke residual versus wood-smoke POA (panel A) and Pittsburgh OOA (Panel E), respectively. The contributions at $m / z, 16,17,18$ and 28 are not included in the regression. Data are from experiment 5 listed in Tables 1 and 2 of the companion manuscript (Grieshop et al., 2009a).

on; Fig. 8c plots the residual spectrum from this experiment after four hours of aging derived using $m / z 60$ as the POA tracer; and Fig. 8e shows the OOA spectrum derived from the ambient data collected during the Pittsburgh Air Quality Study (Ulbrich and Jimenez, 2008; Zhang et al., 2005a). Figures $8 \mathrm{~b}$ and $\mathrm{d}$ show difference spectra. For the wood-smoke experiment shown in Fig. 8, the OA ER estimated using $\mathrm{m} / \mathrm{z}$ 60 and black carbon were within experimental uncertainty; therefore, the residual spectrum (Fig. 8c) derived using $\mathrm{m} / \mathrm{z}$ 60 is the approximate AMS signature of the SOA that was photochemically produced during the experiment (Sage et al., 2008).

The difference spectrum plotted in Fig. $8 \mathrm{~b}$ indicates that the fresh wood-smoke POA is quite distinct from the aged residual; for example, fresh wood-smoke POA has a much larger contribution at higher-mass peaks than the residual spectrum. Oxygenated peaks such as $m / z 44$ are also much more significant in the residual than in the POA spectrum. In 

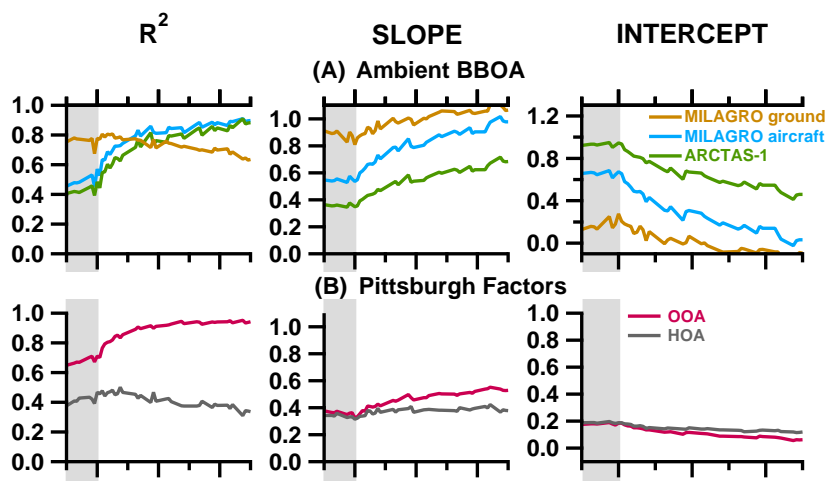

(B) Pittsburgh Factors
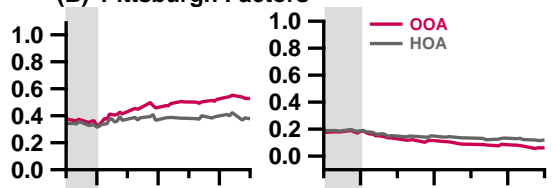

(C) Lab Diesel

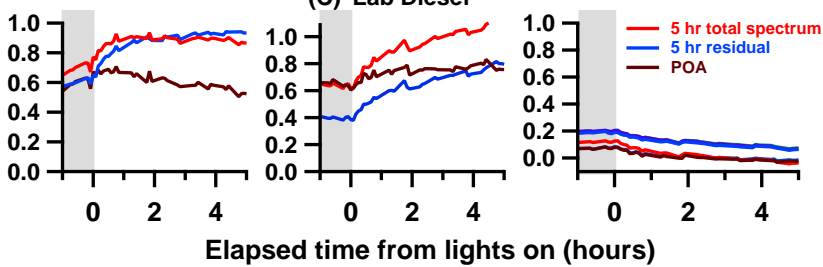

Fig. 9. Comparison of the AMS total OA mass spectra from wood smoke aging experiments with reference spectra from other laboratory and field studies. Each row shows time series of either $R^{2}$, slope or intercept values of linear regressions of the time-evolving wood-smoke spectra versus a set of fixed reference spectra. The first row shows comparisons with BBOA spectra measured in or derived from ambient studies. The second row shows comparisons with ambient HOA and OOA spectra derived from ambient measurements made in Pittsburgh. The third row shows comparisons with spectra from diesel aging experiments (Sage et al., 2008). The first column shows time series of $R^{2}$ value, the second column shows times series of slopes, and the third column shows time series of intercepts. Ambient spectra provided by J. L. Jimenez. Chamber data are from Experiment 5 listed in Tables 1 and 2 of the companion manuscript (Grieshop et al., 2009a).

comparison, the difference spectrum shown in Fig. 8d indicates that this residual spectrum is quite similar to Pittsburgh OOA.

Linear regression of relative spectral intensities can be used to quantitatively compare AMS spectra (Alfarra et al., 2006; Schneider et al., 2006). The approach is illustrated by the scatter plots shown as insets in Fig. 8a and e. $m / z$ 16, 17 and 18 were not included in the linear regressions because they all depend via uncertain fragmentation schemes on $\mathrm{m} / \mathrm{z}$ 44. The contribution at $m / z 28$ has also been excluded because it has traditionally been neglected in the AMS fragmentation scheme. Linear regression of the fresh woodsmoke POA spectrum versus the residual spectrum plotted as an inset in Fig. 8a yields slope, intercept and $R^{2}$ values of $0.42,0.19$ and 0.64 , respectively. This underscores that wood-smoke POA and SOA produced by photo oxidization have distinct spectral signatures in the AMS. As expected based on the difference spectra shown in Figure 8d, a very strong correlation is observed between the residual spectra and Pittsburgh OOA (slope $=1.01$, intercept $=0.00, R^{2}=0.93$ ); therefore photo-oxidation of biomass smoke generates SOA spectrally similar to the OOA observed in the atmosphere. Residual spectra from aging experiments were remarkably uniform across fuel types, burning conditions and aging conditions (including the high- $\mathrm{NO}_{\mathrm{x}}$ experiment, see (Grieshop et al., 2009a) for experimental details). Inter-experiment regressions of residual spectra extracted after $3 \mathrm{~h}$ of aging from all six experiments yield mean and median $R^{2}$ values of 0.94 .

To illustrate how the wood-smoke OA evolves with aging, Fig. 9 compares AMS data from one experiment to eight different reference spectra with each trace indicating the $R^{2}$, slope or intercept of a linear regression of our total OA spectra versus one of the reference spectra. Since we measured an AMS spectrum every $5 \mathrm{~min}$, the results are presented using time series to show the evolving linear correlation of our data versus one of the reference spectra. The contributions at $m / z 16,17,18$ and 28 were excluded from this analysis. Although Figure 9 presents data from a single experiment, the trends discussed below are consistent across our entire set of experiments. In addition, the conclusions hold even if one considers regressions of different subsets of the AMS data, for example $m / z$ larger than 44 (an approach used to mitigate the influence in the $R^{2}$ calculation of the high contributions from smaller masses in AMS spectra).

Figure 9a compares our spectra to ambient AMS data thought to be strongly influenced by biomass burning. We consider two biomass-burning OA (BBOA) factors derived from ambient measurements made in Mexico City during the MILAGRO campaign (Aiken et al., 2008; DeCarlo et al., 2008). One of the Mexico City BBOA factors is based on ground measurements made during the early morning and is therefore thought to be dominated by relatively fresh primary emissions (Aiken et al., 2008). The other Mexico City BBOA factor was derived from measurements made aloft from a C130 aircraft during the late morning and afternoon (DeCarlo et al., 2008); this BBOA factor is thus likely aged in a similar way to the aerosol in our chamber experiments. We also consider a total OA spectra measured in a biomass-burning plume from Siberian forest fires at $5.5 \mathrm{~km}$ of altitude over Alaska from the NASA DC-8 aircraft during the ARCTAS-1 field campaign (all spectra from J. L. Jimenez, pers. comm., 2008). The ARCTAS data are thought to be even more aged than either of the MILAGRO factors.

Of all of the reference spectra considered here, Fig. 9 indicates that our fresh POA data are most correlated with Mexico City BBOA factor derived from the early morning ground-based measurements $\left(R^{2}=0.81\right.$; slope $=0.92$; intercept $=0.08$ ). Emissions from biomass burning are highly variable and this level of correlation is comparable to that observed amongst different fresh wood-smoke POA spectra measured during different source tests. For example, $R^{2}$ values among the POA spectra measured during our experiments ranged between 0.5 to 0.95 , which is comparable to correlations of our POA spectra with other published 
biomass-burning data (Bahreini et al., 2005; Schneider et al., 2006; Ulbrich and Jimenez, 2008; Weimer et al., 2008).

Figure 9 indicates that our fresh POA emissions are not well correlated with the two aged BBOA spectra measured aloft, but that photo-oxidation causes our AMS data to become progressively more correlated to the two aged BBOA factors (MILAGRO airborne and ARCTAS-1). After five hours of aging our AMS data are in excellent agreement with both these factors; for example a linear regression of our data with MILAGRO aloft factor yields an $R^{2}=0.90$, slope $=0.95$ and intercept $=0.05$. However, aging causes our AMS data to become progressively less correlated with the MILAGRO ground-based BBOA factor, consistent with the conclusion that the early morning ground measurements made during MILAGRO were strongly influenced by fresh biomass burning emissions. This highlights the dynamic character of the chemical composition of biomass-burning emissions and that the photochemical age of air masses should be considered when interpreting results from factor analysis of ambient data sets.

Figure $9 \mathrm{~b}$ compares our wood-smoke spectra to HOA and OOA factors derived from the Pittsburgh Air Quality Study dataset (Ulbrich and Jimenez, 2008; Zhang et al., 2005a). Our wood-smoke spectra (fresh or aged) are poorly correlated with the HOA factor. This is not surprising since the HOA factor is associated with fresh emissions from internal combustion sources such as motor vehicles. Our fresh wood-smoke spectra are also not that similar to the ambient OOA factor. This indicates that OOA and wood-smoke POA can be distinguished by factor-analysis techniques. However, aging causes the wood-smoke spectrum to become increasingly correlated with the reference OOA spectrum. After about one hour of aging, the aged wood-smoke spectra has become well-correlated with Pittsburgh OOA spectrum $\left(R^{2}=0.89\right.$, slope $=0.59$, intercept $\left.=0.13\right)$. The small slope indicates that our total wood-smoke OA is less oxidized than the Pittsburgh OOA. This is not surprising since our total spectrum contains significant primary and secondary components. As shown in the inset panel in Fig. 8e, much better agreement is observed if one compares our residual spectrum with the Pittsburgh OOA. The residual spectrum is our best estimate of the spectral signature of the SOA produced during the experiments.

Figure 9c compares our wood-smoke data to reference spectra measured during similar experiments conducted with diesel-engine emissions (Sage et al., 2008; Weitkamp et al., 2007). We consider three reference spectra from the diesel experiments: fresh primary emissions (diesel POA); the total OA spectrum after $5 \mathrm{~h}$ of photo-oxidation; and the residual spectra after $5 \mathrm{~h}$ of photo-oxidation. As expected, there is little correlation between the fresh diesel POA and any of the AMS data from the wood smoke experiments. Therefore we conclude that fresh primary diesel emissions and wood smoke have distinct AMS signatures, consistent with conclusions of previous studies. However, aging of wood smoke creates OA that becomes progressively more similar to the aged diesel emissions. For example, after two hours of aging, the wood-smoke OA spectra are strongly correlated with both the aged diesel OA reference spectrum $\left(R^{2}=0.89\right.$, slope $=0.93$, intercept $\left.=0.02\right)$ and the aged diesel residual reference spectrum $\left(R^{2}=0.88\right.$, slope $=0.63$, intercept $=0.14$ ). Therefore, photo-oxidizing diluted emissions from these very different sources create OA with similar chemical profiles as measured by a unit-mass-resolution AMS. This occurs even though fresh diesel and wood-smoke emissions are chemically distinct - diesel emissions are dominated by saturated species (e.g. straight-chain and cyclic alkanes and aromatic species) (Schauer et al., 1999) while wood smoke is composed of more oxygenated species (e.g. sugars, resin acids and phenols) (Schauer et al., 2001). The combustion conditions inside of a diesel engine are also very different from a wood stove. The similarity of the aged wood-smoke and aged diesel spectra underscores the significant role of atmospheric processing in altering and homogenizing the composition of atmospheric OA.

\section{Discussion and conclusions}

This paper and its companion (Grieshop et al., 2009a) demonstrate that photo-oxidation of diluted woodcombustion emissions in a smog chamber rapidly produces substantial SOA with a chemical character quite distinct from the primary emissions. After several hours of aging under summertime conditions, the unit mass resolution AMS spectrum of this SOA is very similar to spectra of OOA that dominates ambient OA levels in many locations (DeCarlo et al., 2008; Zhang et al., 2005a). However, emissions from a wood fire in a stove are not representative of all biomass-burning emissions. Our experimental conditions fall within the wide range conditions reported by field studies (Grieshop et al., 2009a), but variability is the rule in measurements of biomass-burning emissions. In fact, there is greater variability across the set of published data on biomass-burning plumes than there was in our experiments. For example, some studies report substantial enhancement of OA concentrations in aged plumes similar to what we observed (Lee et al., 2008) while others have only observed oxidation without production of new OA mass (Capes et al., 2008; Hoffer et al., 2006). Further work is clearly needed to better constrain the processes impacting the evolution of this diverse and important class of emissions.

We have now demonstrated that photo-oxidation of emissions from combustion of fossil fuels (Robinson, 2007; Sage et al., 2008) and modern fuels (this work) produce substantial amounts of oxygenated OA with a unit-resolution AMS spectrum closely resembling ambient OOA factors. The similarity between the aged diesel exhaust and aged wood smoke spectra may be due in part to the AMS tracking the changing chemical functionality of the emissions. However, given 
that atmospheric oxidation chemistry is not overly selective, it is also quite possible that the relatively uniform character of OOA is due to photo-oxidation of emissions from different sources producing chemically similar material and not simply an artifact of the fragmentation that occurs inside the AMS. More detailed composition data than that provided by a unit-mass-resolution AMS are required to evaluate this hypothesis.

The results of this study also illustrate some of the strengths of, and challenges with, using factor analysis techniques to interpret ambient AMS data. For example, the spectral characteristics of fresh and aged BBOA are distinct from those of fresh motor-vehicle emissions. Therefore, AMS data can be used to help differentiate emissions from different sources. Our study further reinforces the connection between OOA and OA formed from photo-chemistry. However, with unit-mass-resolution AMS data alone, it is difficult to distinguish OOA (derived from factor analysis of ambient data) from SOA formed from the laboratory aging of biomass burning emissions or diesel emissions. Since OOA is frequently the dominant component of ambient OA (Zhang et al., 2007), this finding has important implications for studies that try to use AMS data to apportion ambient OA to sources (Lanz et al., 2007; Lanz et al., 2008). The data from a unit-mass-resolution AMS alone may not provide enough information to solve this problem. Since diesel exhaust, wood smoke and other emissions have distinct chemical compositions, apportioning OOA to sources will likely require a combination of unit-mass-resolution AMS data and more source-specific, molecular-level information. However, photo-oxidation alters the molecular marker fingerprint of the gas- and condensed-phase emissions (Weitkamp et al., 2008a; Weitkamp et al., 2008b); therefore, apportioning OOA will require understanding the evolution of the molecular composition of the emissions through multiple generations of chemistry.

Acknowledgements. This research was supported by the EPA STAR program through the National Center for Environmental Research (NCER) under grant R833748. This paper has not been subject to EPA's required peer and policy review, and therefore does not necessarily reflect the views of the Agency. No official endorsement should be inferred. The authors gratefully acknowledge Jose-Luis Jimenez for helpful comments and his research group for providing ambient AMS spectra.

Edited by: M. Ammann

\section{References}

Abel, S. J., Haywood, J. M., Highwood, E. J., Li, J., and Buseck, P. R.: Evolution of biomass burning aerosol properties from an agricultural fire in southern Africa, Geophys. Res. Lett., 30, 1783, doi:1710.1029/2003GL017342, 2003.

Aiken, A. C., DeCarlo, P. F., Kroll, J. H., Worsnop, D. R., Huffman, J. A., Docherty, K. S., Ulbrich, I. M., Mohr, C., Kimmel,
J. R., Sueper, D., Sun, Y., Zhang, Q., Trimborn, A., Northway, M., Ziemann, P. J., Canagaratna, M. R., Onasch, T. B., Alfarra, M. R., Prevot, A. S. H., Dommen, J., Duplissy, J., Metzger, A., Baltensperger, U., and Jimenez, J. L.: O/C and OM/OC Ratios of Primary, Secondary, and Ambient Organic Aerosols with HighResolution Time-of-Flight Aerosol Mass Spectrometry, Environ. Sci. Technol., 2, 4478-4485, 2008.

Alfarra, M. R., Paulsen, D., Gysel, M., Garforth, A. A., Dommen, J., Prévôt, A. S. H., Worsnop, D. R., Baltensperger, U., and Coe, H.: A mass spectrometric study of secondary organic aerosols formed from the photooxidation of anthropogenic and biogenic precursors in a reaction chamber, Atmos. Chem. Phys., 6, 52795293, 2006,

http://www.atmos-chem-phys.net/6/5279/2006/.

Alfarra, M. R., Prevot, A. S. H., Szidatt, S., Sandradewi, J., Weimer, S., Lanz, V. A., Schreiber, D., Mohr, M., and Baltensperger, U.: Identification of the mass spectral signature of organic aerosols from wood burning emissions, Environ. Sci. Technol., 41, 57705777, 2007.

Allan, J. D., Delia, A. E., Coe, H., Bower, K. N., Alfarra, M. R., Jimenez, J. L., Middlebrook, A.M., Drewnick, F., Onasch, T. B., Canagaratna, M. R., Jayne, J. T., and Worsnop, D. R.: A generalised method for the extraction of chemically resolved mass spectra from aerodyne aerosol mass spectrometer data, J. Aerosol. Sci., 35, 909-922, 2004.

Allan, J. D., Jimenez, J. L., Williams, P. I., Alfarra, M. R., Bower, K. N., Jayne, J. T., Coe, H., and Worsnop, D. R.: Quantitative sampling using an Aerodyne aerosol mass spectrometer: 1. Techniques of data interpretation and error analysis, J. Geophys. Res.Atmos., 108, D34090, doi:10.1029/2002JD002358, 2003.

An, W. J., Pathak, R. K., Lee, B., and Pandis, S. N.: Aerosol volatility measurement using an improved thermodenuder: Application to secondary organic aerosol, J. Aerosol. Sci., 38, 305-314, 2007.

Bahreini, R., Keywood, M. D., Ng, N. L., Varutbangkul, V., Gao, S., Flagan, R. C., Seinfeld, J. H., Worsnop, D. R., and Jimenez, J. L.: Measurements of secondary organic aerosol from oxidation of cycloalkenes, terpenes, and m-xylene using an Aerodyne aerosol mass spectrometer, Environ. Sci. Technol., 39, 5674-5688, 2005.

Bond, T. C., Streets, D. G., Yarber, K. F., Nelson, S. M., Woo, J. H., and Klimont, Z.: A technology-based global inventory of black and organic carbon emissions from combustion, J. Geophys. Res.-Atmos., 109, D14203, doi:14210.11029/12003JD003697, 2004.

Canagaratna, M. R., Jayne, J. T., Jimenez, J. L., Allan, J. D., Alfarra, M. R., Zhang, Q., Onasch, T.B., Drewnick, F., Coe, H., Middlebrook, A., Delia, A., Williams, L. R., Trimborn, A. M., Northway, M. J., DeCarlo, P. F., Kolb, C. E., Davidovits, P., and Worsnop, D. R.: Chemical and microphysical characterization of ambient aerosols with the aerodyne aerosol mass spectrometer, Mass Spectrom. Rev., 26, 185-222, 2007.

Capes, G., Johnson, B., McFiggans, G., Williams, P. I., Haywood, J., and Coe, H.: Aging of biomass burning aerosols over West Africa: Aircraft measurements of chemical composition, microphysical properties, and emission ratios, J. Geophys. Res.Atmos., 113, D00C15, doi:10.1029/2008JD009845, 2008.

Crosier, J., Jimenez, J. L., Allan, J. D., Bower, K. N., Williams, P. I., Alfarra, M. R., Canagaratna, M. R., Jayne, J. T., Worsnop, D. R., and Coe, H., Technical Note: Description and use of the 
new Jump Mass Spectrum mode of operation for the Aerodyne Quadrupole Aerosol Mass Spectrometers (Q-AMS), Aerosol Sci. Technol., 41, 865-872, 2007.

de Gouw, J., Brock, C., Atlas, E., Bates, T., Fehsenfeld, F., Goldan, P., Holloway, J., Kuster, W., Lerner, B., and Matthew, B.: Sources of particulate matter in the northeastern United States in summer: 1. Direct emissions and secondary formation of organic matter in urban plumes, J. Geophys. Res, 113, D08301, doi:10.1029/2007JD009243, 2008.

de Gouw, J. A., Middlebrook, A. M., Warneke, C., Goldan, P. D., Kuster, W. C., Roberts, J. M., Fehsenfeld, F. C., Worsnop, D. R., Canagaratna, M. R., Pszenny, A. A. P., Keene, W. C., Marchewka, M., Bertman, S. B., and Bates, T. S.: Budget of organic carbon in a polluted atmosphere: Results from the New England Air Quality Study in 2002, J. Geophys. Res.-Atmos., 110, doi:10.1029/2004JD005623, 2005.

DeCarlo, P. F., Dunlea, E. J., Kimmel, J. R., Aiken, A. C., Sueper, D., Crounse, J., Wennberg, P. O., Emmons, L., Shinozuka, Y., Clarke, A., Zhou, J., Tomlinson, J., Collins, D. R., Knapp, D., Weinheimer, A. J., Montzka, D. D., Campos, T., and Jimenez, J. L.: Fast airborne aerosol size and chemistry measurements above Mexico City and Central Mexico during the MILAGRO campaign, Atmos. Chem. Phys., 8, 4027-4048, 2008, http://www.atmos-chem-phys.net/8/4027/2008/.

Grieshop, A. P., Donahue, N. M., and Robinson, A. L.: Is the Gas-Particle Partitioning in alpha-Pinene Secondary Organic Aerosol Reversible?, Geophys. Res. Lett., 34, L14810, doi:14810.11029/12007GL029987, 2007.

Grieshop, A. P., Logue, J. M., Donahue, N. M., and Robinson, A. L.: Laboratory investigation of photochemical oxidation of organic aerosol from wood fires 1: measurement and simulation of organic aerosol evolution, Atmos. Chem. Phys., 9, 1263-1277, 2009a, http://www.atmos-chem-phys.net/9/1263/2009/.

Grieshop, A. P., Miracolo, M. A., Donahue, N. M., and Robinson, A. L.: Constraining the Volatility Distribution and Gas-Particle Partitioning of Combustion Aerosols Using Isothermal Dilution and Thermodenuder Measurements, Environmental Science and Technology, in press, 2009b.

Herndon, S. C., Onasch, T. B., Wood, E. C., Kroll, J. H., Canagaratna, M. R., Jayne, J. T., Zavala, M. A., Knighton, W. B., Mazzoleni, C., Dubey, M. K., Ulbrich, I. M., Jimenez, J. L., Seila, R., Gouw, J. A. d., Foy, B. d., Fast, J., Molina, L. T., Kolb, C. E., and Worsnop, D. R.: The Correlation of Secondary Organic Aerosol with Odd Oxygen in a Megacity Outflow, Geophys. Res. Lett., 35, L15804, doi:10.1029/2008GL034058, 2008.

Hoffer, A., Gelencser, A., Blazso, M., Guyon, P., Artaxo, P., and Andreae, M. O.: Diel and seasonal variations in the chemical composition of biomass burning aerosol, Atmos. Chem. Phys., 6, 3505-3515, 2006, http://www.atmos-chemphys.net/6/3505/2006/.

Huffman, J. A., Docherty, K. S., Aiken, A. C., Cubison, M. J., Ulbrich, I. M., DeCarlo, P. F., Sueper, D., Jayne, J. T., Worsnop, D. R., Ziemann, P. J., and Jimenez, J. L.: Chemically-resolved aerosol volatility measurements from two megacity field studies, Atmos. Chem. Phys. Discuss., 9, 2645-2697, 2009, http://www.atmos-chem-phys-discuss.net/9/2645/2009/.

Jimenez, J. L., Jayne, J. T., Shi, Q., Kolb, C. E., Worsnop, D. R., Yourshaw, I., Seinfeld, J. H., Flagan, R. C., Zhang, X. F., Smith, K. A., Morris, J. W., and Davidovits, P.: Ambient aerosol sam- pling using the Aerodyne Aerosol Mass Spectrometer, J. Geophys. Res.-Atmos., 108, D78425, doi:10.1029/2001JD001213, 2003.

Koppmann, R., von Czapiewski, K., and Reid, J. S.: A review of biomass burning emissions, part I: gaseous emissions of carbon monoxide, methane, volatile organic compounds, and nitrogen containing compounds, Atmos. Chem. Phys. Discuss., 5, 10455-10516, 2005, http://www.atmos-chem-physdiscuss.net/5/10455/2005/.

Lanz, V. A., Alfarra, M. R., Baltensperger, U., Buchmann, B., Hueglin, C., and Prevot, A. S. H.: Source apportionment of submicron organic aerosols at an urban site by factor analytical modelling of aerosol mass spectra, Atmos. Chem. Phys., 7, 15031522, 2007, http://www.atmos-chem-phys.net/7/1503/2007/.

Lanz, V. A., Alfarra, M. R., Baltensperger, U., Buchmann, B., Hueglin, C., Szidat, S., Wehrli, M. N., Wacker, L., Weimer, S., Caseiro, A., Puxbaum, H., and Prevot, A. S. H.: Source attribution of submicron organic aerosols during wintertime inversions by advanced factor analysis of aerosol mass spectra, Environ. Sci. Technol., 42, 214-220, 2008.

Lee, S., Kim, H. K., Yan, B., Cobb, C. E., Hennigan, C., Nichols, S., Chamber, M., Edgerton, E. S., Jansen, J. J., Hu, Y. T., Zheng, M., Weber, R. J., and Russell, A. G.: Diagnosis of aged prescribed burning plumes impacting an urban area, Environ. Sci. Technol., 42, 1438-1444, 2008.

Lipsky, E. M. and Robinson, A. L.: Effects of dilution on fine particle mass and partitioning of semivolatile organics in diesel exhaust and wood smoke, Environ. Sci. Technol., 40, 155-162, 2006.

Milosavljevic, I., Oja, V., and Suuberg, E. M.: Thermal effects in cellulose pyrolysis: Relationship to char formation processes, Ind. Eng. Chem. Res., 35, 653-662, 1996.

Nopmongcol, U., Khamwichit, W., Fraser, M. P., and Allen, D. T.: Estimates of heterogeneous formation of secondary organic aerosol during a wood smoke episode in Houston, Texas, Atmos. Environ., 41, 3057-3070, 2007.

Reid, J., Hobbs, P., Ferek, R., Blake, D., Martins, J., Dunlap, M., and Liousse, C.: Physical, chemical, and optical properties of regional hazes dominated by smoke in Brazil, J. Geophys. Res., 103, 32059-32080, 1998.

Reid, J. S., Koppmann, R., Eck, T. F., and Eleuterio, D. P., A review of biomass burning emissions part II: intensive physical properties of biomass burning particles, Atmos. Chem. Phys., 5, 799825, 2005, http://www.atmos-chem-phys.net/5/799/2005/.

Robinson, A. L., Donahue, N. M., Shrivastava, M. K., Weitkamp, E. A., Sage, A. M., Grieshop, A. P., Lane, T. E., Pierce, J. R., Pandis, S. N.: Rethinking Organic Aerosols: Semivolatile Emissions and Photochemical Aging, Science, 315, 1259-1262, 2007.

Robinson, A. L., Subramanian, R., Donahue, N. M., BernardoBricker, A., and Rogge, W. F.: Source apportionment of molecular markers and organic aerosol. 2. Biomass smoke, Environ. Sci. Technol., 40, 7811-7819, 2006.

Sage, A. M., Weitkamp, E., Donahue, N. M., and Robinson, A. L.: Evolving mass spectra of the oxidized component of organic aerosol: Results from aerosol mass spectrometer analyses of aged diesel emissions, Atmos. Chem. Phys., 8, 1139-1152, 2008, http://www.atmos-chem-phys.net/8/1139/2008/.

Schauer, J. J., Kleeman, M. J., Cass, G. R., and Simoneit, B. R. T.: Measurement of emissions from air pollution sources. 2. C- 
1 through C-30 organic compounds from medium duty diesel trucks, Environ. Sci. Technol., 33, 1578-1587, 1999.

Schauer, J. J., Kleeman, M. J., Cass, G. R., and Simoneit, B. R. T.: Measurement of emissions from air pollution sources. 3. C1-C-29 organic compounds from fireplace combustion of wood, Environ. Sci. Technol., 35, 1716-1728, 2001.

Schauer, J. J., Rogge, W. F., Hildemann, L. M., Mazurek, M. A., and Cass, G. R.: Source apportionment of airborne particulate matter using organic compounds as tracers, Atmos. Environ., 30, 3837-3855, 1996.

Schneider, J., Weimer, S., Drewnick, F., Borrmann, S., Helas, G., Gwaze, P., Schmid, O., Andreae, M. O., and Kirchner, U.: Mass spectrometric analysis and aerodynamic properties of various types of combustion-related aerosol particles, Int. J. Mass Spectrom., 258, 37-49, 2006.

Shrivastava, M. K., Lipsky, E. M., Stanier, C. O., and Robinson, A. L.: Modeling semivolatile organic aerosol mass emissions from combustion systems, Environ. Sci. Technol., 40, 26712677, 2006.

Simoneit, B. R. T., Schauer, J. J., Nolte, C. G., Oros, D. R., Elias, V. O., Fraser, M.P., Rogge, W. F., and Cass, G. R.: Levoglucosan, a tracer for cellulose in biomass burning and atmospheric particles, Atmos. Environ., 33, 173-182, 1999.

Subramanian, R., Donahue, N. M., Bernardo-Bricker, A., Rogge, W. F., and Robinson, A. L.: Contribution of motor vehicle emissions to organic carbon and fine particle mass in Pittsburgh, Pennsylvania: Effects of varying source profiles and seasonal trends in ambient marker concentrations, Atmos. Environ., 40, 8002-8019, 2006.

Takegawa, N., Miyakawa, T., Kawamura, K., and Kondo, Y.: Contribution of selected dicarboxylic and omega-oxocarboxylic acids in ambient aerosol to the $\mathrm{m} / \mathrm{z} 44$ signal of an aerodyne aerosol mass spectrometer, Aerosol. Sci. Technol., 41, 418-437, 2007.

Ulbrich, I., Canagaratna, M., Zhang, Q., Worsnop, D., and Jimenez, J.: Interpretation of organic components from positive matrix factorization of aerosol mass spectrometric data, Atmos. Chem. Phys. Discuss., 8, 6729-6791, 2008, http://www.atmos-chem-phys-discuss.net/8/6729/2008/.

Ulbrich, I. M. and Jimenez, J. L.: AMS Spectral Database, http: //cires.colorado.edu/jimenez-group/AMSsd/, 2008

Volkamer, R., Jimenez, J. L., San Martini, F., Dzepina, K., Zhang, Q., Salcedo, D., Molina, L. T., Worsnop, D. R., and Molina, M. J.: Secondary organic aerosol formation from anthropogenic air pollution: Rapid and higher than expected, Geophys. Res. Lett., 33, L17811, doi:17810.11029/12006GL026899, 2006.
Weimer, S., Alfarra, M. R., Schreiber, D., Mohr, M., Prevot, A. S. H., and Baltensperger, U.: Organic aerosol mass spectral signatures from wood-burning emissions: Influence of burning conditions and wood type, J. Geophys. Res.-Atmos., 113, D10304 doi:10.1029/2007JD009309, 2008.

Weitkamp, E. A., Hartz, K. E. H., Sage, A. M., Donahue, N. M., and Robinson, A. L.: Laboratory measurements of the heterogeneous oxidation of condensed-phase organic molecular makers for meat cooking emissions, Environ. Sci. Technol., 42, 51775182, 2008a.

Weitkamp, E. A., Lambe, A. T., Donahue, N. M., and Robinson, A. L.: Laboratory Measurements of the Heterogeneous Oxidation of Condensed-Phase Organic Molecular Makers for Motor Vehicle Exhaust, Environ. Sci. Technol., 42, 7950-7956, 2008b.

Weitkamp, E. A., Sage, A. M., Pierce, J. R., Donahue, N. M., and Robinson, A. L.: Organic aerosol formation from photochemical oxidation of diesel exhaust in a smog chamber, Environ. Sci. Technol., 41, 6969-6975, 2007.

Zhang, Q., Alfarra, M. R., Worsnop, D. R., Allan, J. D., Coe, H., Canagaratna, M. R., and Jimenez, J. L.: Deconvolution and quantification of hydrocarbon-like and oxygenated organic aerosols based on aerosol mass spectrometry, Environ. Sci. Technol., 39, 4938-4952, 2005a.

Zhang, Q., Worsnop, D., Canagaratna, M., and Jimenez, J.: Hydrocarbon-like and oxygenated organic aerosols in Pittsburgh: insights into sources and processes of organic aerosols, Atmos. Chem. Phys., 5, 3289-3311, 2005b, http://www.atmos-chem-phys.net/5/3289/2005/.

Zhang, Q., Jimenez, J. L., Canagaratna, M. R., Allan, J. D., Coe, H., Ulbrich, I., Alfarra, M. R., Takami, A., Middlebrook, A. M., Sun, Y. L., Dzepina, K., Dunlea, E., Docherty, K., DeCarlo, P. F., Salcedo, D., Onasch, T., Jayne, J. T., Miyoshi, T., Shimono, A., Hatakeyama, S., Takegawa, N., Kondo, Y., Schneider, J., Drewnick, F., Weimer, S., Demerjian, K., Williams, P., Bower, K., Bahreini, R., Cotrell, L., Griffin, R. J., Rautiainen, J., Sun, J. Y., Zhang, Y. M., and Worsnop, D. R.: Ubiquity and Dominance of Oxygenated Species in Organic Aerosols in Anthropogenically-Influenced Northern Hemisphere Mid-latitudes, Geophys. Res. Lett., 34, L13801, doi:13810.11029/12007GL029979, 2007. 